\title{
CIÊNCIA E EDUCAÇÃO ESCOLAR EM TEMPOS DE OBSCURANTISMO
}

\author{
SCIENCE AND SCHOOL EDUCATION IN TIMES OF OBSCURANTISM
}

\author{
Márcia Morschbacher ${ }^{1}$ \\ Universidade Federal de Santa Maria (UFSM)
}

\section{RESUMO}

Este trabalho bibliográfico analisa a relação entre ciência e educação escolar, tendo em conta a atual conjuntura de acirramento da contradição entre as forças produtivas e as relações de produção e da luta de classes, assim como de recrudescimento do obscurantismo. Aborda a desqualificação da formação dos trabalhadores como expressão da tendência ao rebaixamento ao custo da força de trabalho e como esta se articula ao projeto obscurantista de educação que se institucionaliza no país. Ainda, analisa a relação entre ciência, formação humana e educação escolar. Conclui que o interdito ao acesso ao conhecimento nas suas formas mais elaboradas, em especial, a ciência, responde aos interesses hegemônicos de manutenção da ordem vigente e que a defesa da ciência, da educação escolar e da escola coloca-se como uma agenda fundamental no enfrentamento ao obscurantismo nas suas diversas expressões.

Palavras-Chave: Educação Escolar; Ciência; Obscurantismo.

\section{ABSTRACT}

This bibliographical paper analyzes the relation between science and school education, considering the current situation of worsening the contradiction among the productive forces and the relations of production and class struggle, as well as the upsurge of obscurantism. It addresses the disqualification of the training of workers as an expression of the tendency to downgrade the cost of the labor force and how it is linked to the obscurantist education project that is institutionalized in the country. Still, it analyzes the relationship between science, human formation and school education. It is concluded that the prohibited on access to knowledge in its most elaborate forms, in particular, the science, responds to hegemonic interests in

\footnotetext{
1 Doutora em Educação pela Universidade Federal da Bahia (UFBA). Professora adjunta da Universidade Federal de Santa Maria (UFSM). E-mail:mm.edufisica@yahoo.com.br
} 
maintaining the current order and that the defense of science, school education and the school is a fundamental agenda in confrontation against the obscurantism in its various expressions.

Keywords: School education; Science; obscurantism.

\section{Introdução}

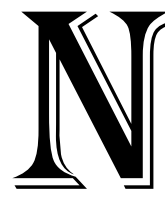

Teste trabalho, analisamos a relação entre ciência e educação escolar, tendo em conta a atual conjuntura de acirramento da contradição entre as forças produtivas e as relações de produção e luta de classes, assim como, no quadro das ideias, de avanço do obscurantismo.

Nesse sentido, no decurso de nossa exposição, problematizamos a desqualificação da formação dos trabalhadores e das trabalhadoras como expressão da tendência ao rebaixamento do custo da força de trabalho na atual conjuntura de acirramento da contradição entre as forças produtivas e as relações de produção e da luta de classes e de intensificação da ofensiva imperialista sobre os povos. Ainda, articulado à caracterização da conjuntura, abordamos o fenômeno do obscurantismo.

No tocante a este, procuramos defini-lo e situá-lo no quadro de um projeto de educação que se institucionaliza no país e que, articulado à política ultraneoliberal em desenvolvimento no país, conduz, no âmbito da educação escolar, ao interdito ao acesso ao conhecimento nas suas formas elaboradas. Neste debate, buscamos situar os interesses de classe que fundam o obscurantismo em geral e, em particular, na educação escolar.

A partir da análise dos fundamentos teórico-metodológicos da relação entre ciência e educação escolar, intentamos evidenciar que a apropriação das objetivações culturais da humanidade nas suas formas mais elaboradas consiste em um dos focos de ataque do obscurantismo, devido ao papel do conhecimento na direção e no alcance da ação humana na realidade concreta em sentido imediato, mediato e histórico.

Trata-se de um estudo bibliográfico que, apoiado na dialética materialista e na pedagogia histórico-crítica, apresenta o seguinte percurso de exposição: a) a desqualificação da formação dos trabalhadores e das trabalhadoras como expressão da tendência ao rebaixamento do custo da força de trabalho no modo de produção capitalista em sua etapa imperialista de desenvolvimento; b) breves notas sobre o recrudescimento do obscurantismo 
no Brasil e sua relação com a educação escolar; c) análise dos fundamentos teóricometodológicos da relação entre ciência e educação escolar; d) conclusões (síntese).

\section{A tendência ao rebaixamento do valor da força de trabalho}

O modo de produção capitalista, no seu atual estágio de desenvolvimento, nomeadamente, o imperialista (LÊNIN, 2007), é marcado pela agudização de suas contradições, em particular, a contradição entre capital e trabalho (ARRIZABALO MONTORO, 2014). Vejamos alguns exemplos: produzimos ciência e tecnologia de ponta e temos 758 milhões de adultos com baixa alfabetização no mundo (em que as mulheres representam 63\% deste número) ${ }^{2}$; produzimos alimentos suficientes para alimentar toda a população mundial e uma pessoa morre de fome a cada quatro segundos no mundo3; alcançamos avanços importantes no diagnóstico e tratamento de doenças e agrava-se a mortalidade relacionada a doenças diretamente ligadas às condições socioeconômicas ${ }^{4}$ e à produção e consumo de alimentos com agrotóxicos ${ }^{5}$. As guerras atingiram números expressivos no último período: 63 em 2008, 51 em 2012 e 42 em $2014^{6}$ e; no ano de 2015, cerca de 795 milhões de pessoas passavam fome no mundo, sendo que, destas, 172 milhões de pessoas enfrentavam as consequências de guerras ${ }^{7}$.

No Brasil, no período em que este manuscrito é elaborado, a democracia foi aviltada ${ }^{8}$, constituindo-se um estado de exceção ainda não superado, direitos historicamente

${ }^{2}$ Cf. relatório global da Organização das Nações Unidas para a Educação, a Ciência e a Cultura (Unesco) sobre Aprendizagem e Educação de Adultos (UNESCO, 2017).

${ }^{3}$ Cf. FAO (2016) e landoli (2016).

${ }^{4}$ Ver Assad (2010).

${ }^{5}$ Ver Carneiro et al. (2015).

${ }^{6}$ Cf. relatório do Instituto Internacional de Estudos Estratégicos (IISS) (2015).

7 Cf. Terra (2015).

8 Em 2016, tem início no país um Estado de exceção constituído a partir do rompimento com o Estado democrático de direito, mediante um golpe jurídico, parlamentar e midiático, tendo como artífices a burguesia nacional e o imperialismo estadunidense, que é consumado pelas instituições do Estado brasileiro. A presidenta Dilma Rousseff, legitimamente eleita e condenada sem crime de responsabilidade, é deposta. O governo ilegítimo que é posto no poder, com o apoio das referidas instituições, realiza uma severa ofensiva aos direitos dos trabalhadores com contrarreformas (trabalhista, previdenciária, Ensino Médio, etc.). Os trabalhadores brasileiros, apoiados em suas organizações, resistem sobretudo por meio de greves gerais e reivindicam a manutenção de seus direitos. Sobre o golpe no Brasil, ver em: Jinkings, Doria e Cleto (2016). Em 2018, mediante um processo duplamente fraudulento (a primeira foi a prisão de Luiz Inácio Lula da Silva em uma condenação sem provas, impedindo sua candidatura à Presidência da República em um momento em que as pesquisas eleitorais 0 colocavam em primeiro lugar na preferência dos eleitores e; a segunda, foi a difusão de fake News, como estratégia de campanha do candidato Jair Bolsonaro - posteriormente eleito -, pelos diferentes dispositivos de 
conquistados pelos trabalhadores brasileiros são atacados (trabalhistas, previdenciários, acesso à educação, saúde, etc.), os orçamentos públicos são $\operatorname{cortados}^{9}$, o Ensino Médio é reformado em uma perspectiva de atendimento aos interesses do capital ${ }^{10}$, estados da federação enfrentam uma crise orçamentária sem precedentes ${ }^{11}$, os conflitos no campo aumentam exponencialmente ${ }^{12}$ e o país retornou ao mapa da fome ${ }^{13}$.

Arrizabalo Montoro (2014) evidencia que o modo de produção capitalista, em sua etapa imperialista de desenvolvimento, apresenta-se crescentemente contraditório. Isto significa que as contradições determinantes à gênese e ao desenvolvimento deste modo de produção e os seus efeitos agudizam-se em patamares sem precedentes na história da humanidade. À guisa de exemplo, mencionamos, no interior da contradição entre capital e trabalho, a agudização da contradição entre as relações capitalistas de produção e as forças produtivas ${ }^{14}$. Em sua etapa imperialista de desenvolvimento, o capitalismo mantém-se como sistema destruindo

redes sociais, contra a candidatura de seu principal oponente, Fernando Haddad. Todo esse processo ocorreu com a conivência das instituições do Estado brasileiro. A partir de 2019, temos um governo de extrema direita que articula o obscurantismo com políticas ultraneoliberais e que, nesse sentido, se empenha na destruição dos serviços públicos e dos direitos dos trabalhadores e das trabalhadoras, na realização de reformas (em especial, a previdenciária, a trabalhista, administrativa, etc.) e de privatizações e na entrega do patrimônio e das riquezas nacionais ao capital estrangeiro. Conforme destaca Dermeval Saviani em entrevista: "Esse descalabro que desabou sobre o nosso país se situa num quadro mais amplo que diz respeito à crise estrutural da forma de sociedade atual baseada no capital." (DUARTE, 2019, p. 4). Ver mais em Duarte (2019).

${ }^{9}$ Além de cortes no orçamento público que vêm desde 2016, recentemente o Estado brasileiro aprovou a Emenda Constitucional 95/2016 limita por 20 anos os recursos públicos.

10 Sobre a contrarreforma do Ensino Médio, ver Frigotto (2016) e Kuenzer (2017).

11 Ver Agência Estado (2019).

12 No ano de 2016, segundo o relatório anual da Comissão Pastoral da Terra (CPT), houve 67 assassinatos no campo (nos últimos 25 anos, este número é inferior somente ao de 2003 (73 assassinatos)), 1.079 ocorrências de conflitos por terra (ações em que há algum tipo de violência, como expulsão, despejo, ameaças de morte, assassinatos, tentativas de assassinato, etc. Este número é o maior dos últimos 32 anos), 1.536 conflitos no campo (soma de conflitos por terra, pela água e trabalhistas - uma média de 4,2 conflitos por dia. Número mais elevado desde 2008) (CANUTO; ANDRADE; LUZ, 2016).

${ }^{13}$ Cf. Braga (2017) e Vargas (2018).

${ }^{14}$ Esta contradição foi mencionada por Karl Marx no Prefácio à Contribuição à Crítica da Economia Política (MARX, 2008). Compreendemos força produtiva como uma categoria econômica e social, em que: "[...] as forças produtivas, em sua inter-relação com as relações de produção (graças à qual adquirem seu caráter social, histórico), não consistem na produtividade, senão no aproveitamento social das potencialidades que, hipoteticamente, pode fornecer esta produtividade" (ARRIZABALO MONTORO, 2014, p. 61, tradução nossa) ("[...] las fuerzas productivas, en su interrelación con las relaciones de producción (gracias a la cual adquieren su carácter social, histórico), no consisten en la productividad, sino en el aprovechamiento social de las potencialidades que, hipotéticamente, puede aportar dicha productividad"). Neste sentido, a referência ao grande desenvolvimento das forças produtivas no capitalismo ascendente consiste em considerar tanto a expansão da produção industrial e o aperfeiçoamento dos meios de produção, mas, também, o desenvolvimento do proletariado como classe e das grandes aglomerações urbanas, nas quais se dá o desenvolvimento da construção civil, dos transportes, das comunicações, da saúde, da educação, etc. e que resultam em melhorias nas condições de vida das populações, em maior ou menor grau, considerando o desenvolvimento desigual e combinado dos países.

Cadernos GPOSSHE On-line, Fortaleza, v. 2, n. Especial, 2019. 
forças produtivas e/ou convertendo forças produtivas em forças destrutivas (ARRIZABALO MONTORO, 2014).

A agudização da contradição entre as relações de produção e o desenvolvimento das forças produtivas demonstram a incompatibilidade entre o capitalismo e 0 atendimento das necessidades básicas da população mundial (ARRIZABALO MONTORO, 2014). Esta tem sido conduzida ao sofrimento em escala planetária ${ }^{15}$. De acordo com Arrizabalo Montoro (2014, p. 25, tradução nossa):

Especialmente em uma situação como a atual, em que as possibilidades materiais que a humanidade atingiu (graças ao aumento da produtividade obtida pela maior qualificação da mão de obra e o progresso científico e técnico), permitiriam cobrir amplamente as necessidades básicas da população mundial. De modo que a frustração desta possibilidade não se deve à escassez, senão aos requisitos derivados da lógica específica que rege o processo de acumulação, isto é, às exigências de rentabilidade da acumulação capitalista. ${ }^{16}$

No cenário da crise do modo de produção capitalista, em que se concretiza a tendência da queda da taxa de lucros e cujo enfrentamento, pelo capital, se dá pela destruição das forças produtivas, tem-se a degradação das condições em que se dá a venda da força de trabalho (desemprego estrutural, aumento do exército industrial de reserva, reformas que eliminam direitos trabalhistas, previdenciários e sociais, aumento da jornada de trabalho, precarização dos contratos de trabalho, etc.) como principal forma lançada pelo capital para enfrentar esta crise. O objetivo principal é a diminuição do valor da força de trabalho (e, por conseguinte, dos custos do trabalho) para suportar a tendência da queda da taxa de lucros que decorre da lógica de acumulação capitalista.

Considerando que a formação do trabalhador é um dos componentes que concorrem para determinar o valor da força de trabalho, o capital lança mão da estratégia de rebaixar e/ou desqualificar esta formação. Ademais, o rebaixamento da formação cumpre mais um papel, o de limitar a capacidade dos trabalhadores e das trabalhadoras de compreender, explicar e

\footnotetext{
${ }_{15}$ Por outro lado, esta situação constitui-se em impulso aos movimentos de massas, com suas especificidades em cada país, que têm como base reivindicações imediatas e mediatas, mas, em última instância, voltam-se ao rompimento com as condições objetivas responsáveis por esta situação. À guisa de exemplo, mencionamos os movimentos de massa do último período (2019-2020) na Argélia, na França e no Chile.

16 "Máxime en uma situación como la actual, en la que las posibilidades materiales que ha alcanzado la humanidad (gracias al aumento de la productividad factible por la mayor cualificación de la mano de obra y el progresso científico y técnico), permitirían cubrir sobradamente las necesidades básicas del conjunto de la población mundial. De modo que la frustración de esta posibilidad no se debe a la escasez, sino a los requerimientos derivados de la lógica específica que rige el proceso de acumulación, esto es, a las exigencias de rentabilidad de la acumulación capitalista" (ARRIZABALO MONTORO, 2014, p. 25).
}

Cadernos GPOSSHE On-line, Fortaleza, v. 2, n. Especial, 2019. 
intervir em uma realidade crescentemente contraditória no seio do capitalismo. Cabe perguntar, portanto, a quem interessa uma formação rebaixada teoricamente, com limitado domínio de conceitos científicos e dos meios de produção da ciência? A quem interessa uma formação que limita a apreensão e explicação radical de fatos da realidade? Considerando as questões abordadas até este momento da exposição, compreende-se a qual projeto e a quais interesses, no interior da luta de classes, o obscurantismo serve.

\section{Breves notas sobre o recrudescimento do obscurantismo no brasil e a educação escolar}

O fenômeno do avanço político e ideológico da direita (e da extrema direita) em muitos países nas últimas décadas encontra amplo reconhecimento (DUARTE, 2018a). Interessa-nos nesta seção, caracterizar de forma sintética uma das expressões deste fenômeno, qual seja, o chamado obscurantismo.

O obscurantismo pode ser definido como um fenômeno social caracterizado pela "difusão de uma atitude de ataque ao conhecimento e à razão, de cultivo de atitudes fortemente agressivas contra tudo aquilo que possa ser considerado ameaçador para posições ideológicas conservadoras e preconceituosas" (DUARTE, 2018a, p. 139). Trata-se da produção e da disseminação de um ambiente de hostilização verbal e física a qualquer ideia ou "comportamento considerados 'esquerdizantes', 'vermelhos' ou 'imorais'” (DUARTE, 2018a, p. 139$)^{17}$.

Duarte (2018b), em outra publicação em que se dedica a pautar o tema, acrescenta que o obscurantismo pode ser definido pela negação entre a dialética entre ignorância e conhecimento ${ }^{18}$. Caracteriza-se por atitudes de ataque ao conhecimento, tanto na sua produção e continuidade de seus avanços e de quem o produz, quanto na difusão do

\footnotetext{
17 Duarte (2018a; 2018b), em suas produções científicas sobre o obscurantismo, refere-se ao fenômeno como "obscurantismo beligerante" por considerar que as suas manifestações, em geral, são intensamente agressivas. ${ }^{18}$ Para o autor, em uma perspectiva dialética e histórica, conhecimento e ignorância são dois polos necessários da ação humana de conhecer a realidade. A ignorância significa que não conhecemos algo: ou desconhecemos sua existência, ou não sabemos explicar objetivamente essa existência. O conhecimento é o avanço na perspectiva de transformar o que não é conhecido em conhecido. Assim: "Então, em certo sentido, o conhecimento é a permanente superação da ignorância que, entretanto, nunca é eliminada" (DUARTE, 2018b, p. 170-171). Se, por um lado, o avanço do conhecimento permite-nos conhecer fenômenos, processo e fatos retirando-os do campo do desconhecido -; por outro, este avanço conduz os seres humanos em sua ação prática a criar novos questionamentos e campos de investigação. Em suma: "o avanço do conhecimento cria, dialeticamente, novos campos de ignorância" (DUARTE, 2018b, p. 171).
}

Cadernos GPOSSHE On-line, Fortaleza, v. 2, n. Especial, 2019. 
conhecimento já descoberto e de quem o difunde. Desse modo: "O obscurantismo vê de maneira estática o conhecido e o desconhecido, não os historiciza, nem os dialetiza" (DUARTE, 2018b, p. 171). Ademais, em geral, expressa-se de uma forma intensamente agressiva, cujas consequências irracionalistas levam-no a "ver inimigos para qualquer direção que olhe" (DUARTE, 2018b, p. 171).

Em nosso país, não se trata de um fenômeno novo, posto que vários movimentos com características obscurantistas foram organizados por vários setores representativos das forças de direita às vésperas do golpe civil-militar de 1964 (DUARTE, 2018a). Na atualidade, o obscurantismo se apresenta com algumas peculiaridades como o emprego da internet para a difusão de "fake news": "o obscurantismo é o maior beneficiário das 'fake news"' (DUARTE, 2018a, p. 139).

Duarte (2019) observa que, recententemente no Brasil, o obscurantismo foi convertido em política de Estado. No campo da educação, as forças políticas que tomaram o poder político em nosso país em 2019 mostram-se engajadas em uma guerra contra os professores e professoras, as escolas públicas, as universidades públicas e contra a produção e difusão do conhecimento. Tem-se uma articulação entre a ideologia obscurantista com o neoliberalismo radical, em que: "Nesse contexto, é quase inevitável o receio de que o futuro que nos espera seja o da barbárie incontrolável" (DUARTE, 2019, p. 10).

A articulação entre a ideologia obscurantista com o neoliberalismo radical pode ser compreendida ao ter-se em conta que a origem do obscurantismo está no agravamento da crise do modo de produção capitalista, que tem conduzido a humanidade à barbárie (DUARTE, 2018b). Com a finalidade de manter as taxas de lucro e a dominação imperialista, a classe capitalista tem se mostrado cada vez mais agressiva na aplicação de medidas que visam protelar o anunciado colapso do sistema - vide a ofensiva contra os direitos dos trabalhadores e das trabalhadoras em nível mundial, visando a redução do custo da força de trabalho. Nesse sentido, Duarte (2018b, p. 175) pontua que: "O obscurantismo beligerante, portanto, é uma atitude que defende um tipo de vida, de sociedade, de relações humanas, de relações sociais que se caracteriza pela generalização da barbárie. É isso que o capitalismo está produzindo".

Nacif e Silva Filho (2019) refere-se à institucionalização de um projeto de educação obscurantista no governo central do Brasil a partir de 2019. Conforme os autores:

São inúmeros exemplos nessa direção: a defesa de políticas públicas alinhadas ao projeto Escola sem Partido, a defesa da introdução nos currículos de visões religiosas 
sobre a criação do universo, a hostilidade oficializada à obra de Paulo Freire, a indicação aos pais para rasgar cadernetas sobre Educação sexual, a relativização de fatos históricos como a ditadura militar (que não teria existido) ou a escravidão (que, segundo esse anti-intelectualismo, não foi tão brutal como a historiografia sobre o tema busca relatar). (NACIF; SILVA FILHO, 2019, p. 241).

Em particular quanto ao movimento autointitulado "Escola Sem Partido", Duarte (2018) expressa que:

Ao contrário do que preconizam seus defensores, esse movimento não visa a defesa da escola diante de possíveis ações de proselitismo político-partidário ou de constrangimento ideológico. Sua real finalidade é a criação de um ambiente de censura ideológica, ética e política dos professores, dos currículos e dos materiais pedagógicos, de maneira a se submeter a escola pública aos ditames das mais reacionárias e irracionalistas concepções de mundo existentes na sociedade contemporânea. Não se trata, como pensam inclusive alguns dos críticos desse movimento, apenas da censura a alguns temas como no caso daquilo que os defensores do movimento chamam de "ideologia de gênero". A tentativa de proibição da discussão de questões de gênero nas escolas públicas é apenas a face mais visível de uma visão de mundo que, no limite, se opõe à difusão do pensamento científico, da riqueza artística e da reflexão filosófica. (DUARTE, 2018, p. 139-140, grifo nosso).

Destes exemplos, considerando o objetivo deste artigo, destacamos a oposição "à difusão do pensamento científico, da riqueza artística e da reflexão pedagógica" (DUARTE, 2018, p. 140) como mote central de nosso debate na relação entre ciência e educação escolar em tempos de recrudescimento do obscurantismo no país. Em suma, o obscurantismo, no campo educacional, tem como uma de suas consequências o interdito ao acesso ao conhecimento nas suas formas mais elaboradas e a sua substituição por afirmações sem relação com a objetividade material da realidade. O obscurantismo procura conduzir os indivíduos à ignorância em detrimento da explicação científica dos fatos e à disseminação e reprodução de mitos, dogmas e preconceitos em detrimento da transmissão e apropriação da ciência e do conhecimento sobre os meios de produzi-la. O obscurantismo procura deturpar a função social da escola (a socialização do saber sistematizado) e pretende convertê-la em instrumento de difusão de suas ideias irracionalistas e conservadoras.

Perguntamos, nesse sentido, em uma conjuntura de acirramento da contradição entre as relações de produção e o desenvolvimento das forças produtivas, de tendência ao colapso do capitalismo como modo de produção e de intensificação da ofensiva do imperialismo sobre os povos; em uma conjuntura de ataques contra os direitos da classe trabalhadora e de tendência à explosão social (visto que o capitalismo já não é capaz de atenuar o sofrimento das massas de trabalhadores e trabalhadoras, senão de intensificá-lo): a que projeto 
(educacional e histórico) e a quem interessa este interdito ao conhecimento no âmbito da ciência, das artes e da filosofia? De acordo com Saviani (2012, p. 86):

Os ideólogos da burguesia colocavam a necessidade de educação de forma mais geral e, nesse sentido, cumpriam o papel de hegemonia, ou seja, de articular toda a sociedade em torno dos interesses que se contrapunham à dominação feudal. Enquanto a burguesia era revolucionária, isso fazia sentido; quando ela se consolidou no poder, a questão principal já não era superar a velha ordem, o Antigo Regime. Esse, com efeito, já fora superado, e a burguesia, em consequência, já se tornara classe dominante; nesse momento, o problema principal da burguesia passa a ser evitar as ameaças e neutralizar as pressões para que se avance no processo revolucionário e se chegue a uma sociedade socialista. A burguesia, então, torna-se conservadora e passa a ter dificuldades ao lidar com o problema da escola, pois a verdade é sempre revolucionária. Enquanto a burguesia era revolucionária, ela possuía interesse na verdade. Quando passa a ser conservadora, a verdade então a incomoda, choca-se com os seus interesses. Isso ocorre porque a verdade histórica evidencia a necessidade das transformações, as quais, para a classe dominante - uma vez consolidada no poder - não são interessantes; ela tem interesse na perpetuação da ordem existente.

Em nosso ponto de vista, Saviani (2012) elucida esta questão, demonstrando os interesses de classe postos na relação entre ciência e educação escolar. Esta reflexão auxilia na compreensão do fenômeno do recrudescimento do obscurantismo na sociedade brasileira, em especial, no âmbito da institucionalização de um projeto de educação obscurantista.

Em uma conjuntura de agudização das contradições do modo de produção capitalista e, diante da iminência de uma explosão social decorrente da situação posta, o obscurantismo serve de instrumento para a manutenção da ordem estabelecida na perspectiva da produção de consensos pela autoritarismo e pela disseminação do ódio e da ignorância.

\section{Análise dos fundamentos teórico-metodológicos da relação entre ciência e educação escolar}

Nesta seção, analisamos a concepção de ser humano, de conhecimento/ciência e de trabalho educativo com base na dialética materialista e na pedagogia histórico-crítica. Consideramos que a abordagem destas categorias cumpre o papel de debater sobre a relação entre ciência e educação escolar, e de oferecer um instrumento teórico para o enfrentamento ao obscurantismo.

Em oposição a uma concepção criacionista e/ou a uma concepção biologicista de ser humano, compreendemos o ser humano como um ser histórico-social. O ser humano, nessa perspectiva, "é um ser de natureza social, que tudo o que tem de humano nele provém da sua 
vida em sociedade, no seio da cultura criada pela humanidade" (LEONTIEV, 1978, p. 261, grifos do autor). Em suma, os seres humanos não nascem humanos, tornam-se humanos (humanizam-se). Isso não significa, contudo, desconsiderar os componentes biológicos envolvidos no seu desenvolvimento, mas evidenciar que as leis determinantes a este processo são as leis sócio históricas. Conforme Leontiev (1978, p. 264):

O homem não está evidentemente subtraído ao campo de acção das leis biológicas. $O$ que é verdade é que as modificações biológicas hereditárias não determinam o desenvolvimento sócio-histórico do homem e da humanidade; este é doravante movido por outras forças que não as leis da variação e da hereditariedade biológicas.

O salto qualitativo primordial dos seres humanos comparativamente aos animais é sua "atividade criadora e produtiva"19, isto é, o trabalho: "atividade especificamente humana pela qual o objetivo que é antecipado mentalmente se realiza praticamente" (SAVIANI, 2014, p. 5). A antecipação mental é a capacidade de formular em ideia aquilo que se pretende realizar e tem como base a representação, no pensamento, da realidade. A representação, entretanto, não se restringe ao reflexo imediato do real, tendo em conta que o ser humano é capaz de transcendê-lo, antecipando as possibilidades de sua transformação e orientando sua ação de forma intencional (MARX, 1990). Esta capacidade aperfeiçoa-se, historicamente, na medida em que os seres humanos produzem e reproduzem a vida e em que se amplia, por esta atividade, o domínio das possibilidades e potencialidades da matéria. Nessa perspectiva:

Pela sua actividade, os homens não fazem senão adaptar-se à natureza. Eles modificam-na em função do desenvolvimento das suas necessidades. Criam os objectos que devem satisfazer as suas necessidades e igualmente os meios de produção destes objectos, dos instrumentos às máquinas mais complexas. Constroem as habitações, produzem as suas roupas e outros bens materiais. Os progressos realizados na produção de bens materiais são acompanhados pelo desenvolvimento da cultura dos homens; o seu conhecimento do mundo circundante e deles mesmos enriquece-se, desenvolvem-se a ciência e a arte (LEONTIEV, 1978, p. 265).

Com a complexificação das relações sociais, o que ocorre com o desenvolvimento das forças produtivas e das relações de produção nos diferentes períodos históricos, complexificase o conhecimento adquirido sobre a realidade pelo processo de transformação material da natureza e desenvolvem-se gradativamente formas mais sofisticadas de obter este conhecimento - chegando à ciência ${ }^{20}$. A complexificação aludida também resulta no

19 Cf. Leontiev (1978).

${ }^{20}$ Atente-se para o fato de que esta complexificação se desenvolve no quadro de diferentes modos de produção e da luta de classes.

Cadernos GPOSSHE On-line, Fortaleza, v. 2, n. Especial, 2019. 
desenvolvimento de procedimentos e de instituições voltadas para a transmissão sistemática deste patrimônio da humanidade: a escola (SAVIANI, 2012).

Cada geração recebe um mundo de objetos, de fenômenos e de relações criado pelas gerações precedentes (LEONTIEV, 1978; MARX; ENGELS, 2007). Ela "apropria-se das riquezas deste mundo participando no trabalho, na produção e nas diversas formas de actividade social e desenvolvendo assim as aptidões especificamente humanas que se cristalizaram, encarnaram nesse mundo" (LEONTIEV, 1978, p. 266). A apropriação das objetivações culturais historicamente produzidas pela humanidade é determinante para a humanização dos seres humanos. É nessa direção que Leontiev (1978, p. 267, grifo do autor) afirma que:

Podemos dizer que cada indivíduo aprende a ser um homem. O que a natureza lhe dá quando nasce não the basta para viver em sociedade. É-lhe ainda preciso adquirir o que foi alcançado no decurso do desenvolvimento histórico da sociedade humana.

A partir destes fundamentos, Saviani (2012, p. 13) elabora o conceito de trabalho educativo, definido como: "[...] o ato de produzir, direta e intencionalmente, em cada indivíduo singular, a humanidade que é produzida histórica e coletivamente pelo conjunto dos homens". Ademais, define que o objeto e a tarefa da educação consistem em identificar os elementos culturais que precisam ser assimilados pelos indivíduos para que eles se tornem humanos e descobrir as formas mais adequadas para atingir este objetivo. Interessa à escola, portanto, o conhecimento nas suas formas mais desenvolvidas. Nesse sentido é que Saviani (2012) demarca que a escola existe para cumprir que a necessidade vital de apropriação do conhecimento sistematizado (ciência) pelas novas gerações ${ }^{21}$.

$O$ ensino que promove desenvolvimento é aquele que, mediante o processo de transmissão e de apropriação das objetivações culturais, explora as melhores potencialidades de desenvolvimento dos indivíduos, bem como, as melhores potencialidades humanizadoras

21 Compreendemos a ciência como "atividade humana realizada com a finalidade de conhecer o mundo e nele intervir, de acordo com as condições materiais e com as necessidades determinadas por essas condições. É atividade que é o reflexo das necessidades materiais humanas e do modo como estas necessidades são prática e materialmente produzidas e providas, em profunda conexão com um dado desenvolvimento das forças produtivas e das relações de produção." (MORSCHBACHER, 2019, p. 48). A ciência apresenta uma estrutura interna composta pelos seguintes componentes: a problematização, a sistematicidade, o método, o saber fundamentado como demanda e resultado, e a sua provisoriedade. Esta estrutura interna distingue, em sua forma e em seu conteúdo, a ciência das demais expressões do conhecimento (BARATA-MOURA, 1989). Nesse sentido: "A cientificidade do conhecimento, tendo em conta os pressupostos ontológicos e gnosiológicos da dialética materialista, refere-se de modo decisivo com a penetração e reflexão no pensamento da dinâmica objetiva da realidade. A ciência é a expressão teórica (reflexo no pensamento) da materialidade deveniente do real" (MORSCHBACHER, 2019, p. 56).

Cadernos GPOSSHE On-line, Fortaleza, v. 2, n. Especial, 2019. 
destas objetivações. Em suma, um ensino que produz novas necessidades, situadas para além da cotidianidade capitalista e das formas simplistas e imediatistas de explicação da realidade (DUARTE, 2018a). Conforme Duarte (2018a, p. 144):

\begin{abstract}
A importância dos conteúdos escolares para o aumento do campo de escolhas dos indivíduos das novas gerações conecta-se ao fato de que esses conteúdos nada mais são do que experiência humana acumulada e sintetizada nas ciências, nas artes e na filosofia. Ao se apropriar desses conteúdos, os alunos estão incorporando à sua atividade, sua vida e sua individualidade, condensações da experiência social. Dessa maneira o indivíduo desenvolve a capacidade de agir guiado não apenas por percepções imediatas da realidade ao seu redor, mas pela compreensão das conexões não visíveis entre processos e fenômenos. Isso se aplica à compreensão do movimento tanto da natureza quanto da sociedade. Não é por acaso que os obscurantistas atacam as ciências da sociedade e também as ciências da natureza, além, é claro, da filosofia e das artes.
\end{abstract}

Para Saviani (2019), a educação escolar é o meio mais adequada para a apropriação, pelos trabalhadores, das conquistas históricas da humanidade, "que lhes aguçarão a consciência da necessidade de intervir praticamente para dar continuidade ao processo histórico conduzindo-o a um novo patamar" (p. 5)22.

$\mathrm{O}$ acesso ao conhecimento nas suas formas mais elaboradas atende à necessidade concreta da humanização - da produção do gênero humano nos seres humanos. Sendo a ciência a expressão mais desenvolvida da capacidade humana de conhecer a realidade e de expressá-la na forma de conceitos, esta tem um papel fundamental como conteúdo e meio para a humanização que se materializa pelo trabalho e pelo trabalho educativo (SAVIANI, 2012). A apropriação do conhecimento científico, bem como dos processos de sua produção, potencializam a atividade humana de transformação material da realidade: o domínio dos conceitos, dos processos e das leis que operam na realidade natural e social possibilita aos seres humanos intervir nesta realidade em um patamar qualitativamente superior ${ }^{23}$.

Analisemos os processos de formação humana na sociedade cindida em classes, tendo em conta que humanização e alienação constituem polos contraditórios dos/nos processos de formação humana que se desenvolvem na sociedade desenvolvida no interior da contradição entre capital e trabalho (DUARTE, 2013).

\footnotetext{
${ }^{22}$ Em entrevista concedida a Duarte (2019).

23 Sobre a relação entre teoria e prática, faz-se necessário um registro: a prática não dispensa o conhecimento da realidade, pelo contrário, conhecimento (teoria) e prática constituem uma unidade dialética. É no interior desta unidade que os seres humanos apropriam-se da realidade e produzem e reproduzem a vida de forma qualitativamente superior, empreendendo esforços para superar, ademais, as condições objetivas que limitam 0 seu viver em determinado estágio de desenvolvimento das forças produtivas e das relações de produção.
}

Cadernos GPOSSHE On-line, Fortaleza, v. 2, n. Especial, 2019. 
A forma escolar torna-se a forma predominante de educação no modo de produção capitalista (SAVIANI, 2012). Esta é marcada pela seguinte contradição:

Trata-se da contradição entre a especificidade do trabalho educativo na escola - que consiste na socialização do conhecimento em suas formas mais desenvolvidas - e o fato de que o conhecimento é parte constitutiva dos meios de produção que, nesta sociedade, são propriedade do capital e, portanto, não podem ser socializados (SAVIANI; DUARTE, 2012, p. 2).

A correlação de forças entre as classes em luta impulsionam diferentes projetos que disputam a direção da formação dos trabalhadores e das trabalhadoras na educação escolar, de acordo com os interesses de classe antagônicos - imediatos, mediatos e históricos.

A primeira direção é composta de ações situadas da política educacional até o trabalho pedagógico em sala de aula, incluídos os seus referenciais teóricos, e que funcionam como obstáculos ao desenvolvimento de um sistema nacional de educação pública que permita à classe trabalhadora o acesso ao conhecimento nas suas formas mais elaboradas (SAVIANI; DUARTE, 2012):

O sistema escolar estrutura-se de forma fragmentada, reproduzindo a divisão social do trabalho e a lógica de mercado. O acesso ao conhecimento dá-se de maneira profundamente desigual e seletiva. Tudo isso é camuflado pelo discurso de respeito às diferenças culturais, pelo fetichismo da democratização do acesso ao conhecimento, espontaneamente assegurada pelas tecnologias de informação e pela subordinação dos objetivos da educação escolar a uma lógica de permanente esforço do indivíduo para se adaptar às mudanças constantes das condições de vida e de trabalho, normalmente no sentido da precarização. [...] Concentração, esforço intelectual e abstração para aproximar o aluno aos clássicos do conhecimento são coisas tidas como pertencentes a um mundo inapelavelmente superado (SAVIANI; DUARTE, 2012, p. 2 $3)$.

A outra direção, favorável aos interesses da classe trabalhadora, corresponde à da luta pela efetivação da especificidade da escola: a transmissão e apropriação do conhecimento científico. Esta luta abrange ações organizadas e articuladas nos embates políticos em diversas frentes, como na formação de profissionais da educação qualificados, na produção de conhecimento sobre a educação e na "construção teórica e prática de uma pedagogia que fortaleça o trabalho de produção direta e intencional, em cada aluno e em todos os alunos, do domínio dos conhecimentos necessários ao seu pleno desenvolvimento como seres humanos" (SAVIANI; DUARTE, 2012c, p. 3), na melhoria das condições de trabalho, nos planos de carreira e salários decentes, na luta pela manutenção de direitos historicamente conquistados, etc. 
No atual grau de desenvolvimento das forças produtivas e das relações de produção, em que, no seio da luta de classes, a classe trabalhadora defronta-se com o estado de decomposição deste modo de produção (a sua etapa imperialista) (LÊNIN, 2007), a reivindicação das formas mais desenvolvidas do patrimônio que a humanidade acumulou (no âmbito da filosofia, da arte e da ciência (SAVIANI, 2012)) como conteúdo a ser tratado nos processos de escolarização da classe trabalhadora expressa uma necessidade vital sob um duplo sentido: (a) o da socialização de um meio de produção, pelo fato de que a apropriação da ciência (nos seus processos e resultados) pela classe trabalhadora implica, ainda no seio deste modo de produção, na socialização (mesmo parcial) de uma parte constitutiva dos meios de produção que é o conhecimento científico e; (b) o da possibilidade da ampliação da capacidade humana de conhecer, explicar e intervir na realidade contraditória, seja no quadro de um modo de produção altamente destrutivo e em decomposição que necessita ser superado (mediante a ação organizada e consciente da classe trabalhadora), seja da construção coletiva de uma nova sociedade fundada e planejada na socialização dos meios de produção (SAVIANI; DUARTE, 2012).

O rebaixamento da capacidade de conhecer a realidade, rebaixa, tendencialmente, a possibilidade da ação humana sobre a mesma e, no atual grau de decomposição do modo de produção capitalista, em que este é marcado por contradições crescentemente insustentáveis à manutenção da vida, este fato é inevitavelmente problemático à humanidade, além de contrarrevolucionário. O obscurantismo, na ciência ou na educação escolar, serve a este fim.

\section{Conclusões}

Neste artigo, procuramos analisar a relação entre educação e ciência, considerando a presente conjuntura de acirramento da contradição entre as forças produtivas e as relações de produção e da luta de classes, assim como de recrudescimento do obscurantismo. Em particular o fenômeno do obscurantismo, serviu-nos de mote para o debate engendrado nas seções anteriores.

No quadro da atual conjuntura, abordamos o obscurantismo como fenômeno produzido no interior das contradições do modo de produção capitalista e que serve como instrumento de manutenção deste sistema. Atualmente, converte-se em política de Estado em nosso país 
pelas forças políticas que chegam ao governo (DUARTE, 2019) e serve de referência para o seu projeto de educação.

O obscurantismo, como referência para o desenvolvimento de um projeto educativo, conduz, inevitavelmente, à negação do acesso do saber elaborado às novas gerações tolhendo-Ihe o desenvolvimento da capacidade de compreender, explicar e intervir em uma sociedade crescentemente contraditória. Trata-se da consecução do objetivo de manutenção da ordem e da construção de consensos pela disseminação e naturalização da ignorância, do ódio e da violência. O resultado, conforme atenta Duarte (2018a; 2018b; 2019), é a (re)produção da barbárie. Ademais, este fenômeno concorre para o rebaixamento da formação da classe trabalhadora e do valor da força de trabalho.

A partir da análise dos fundamentos da relação entre ciência e educação escolar, buscamos evidenciar que a apropriação das objetivações culturais da humanidade nas suas formas mais elaboradas (na ciência, na filosofia e na arte) é compromisso político e pedagógico de todos os/as profissionais da educação implicados no enfrentamento ao obscurantismo nas suas diversas expressões. Portanto, a defesa da ciência, da educação escolar e da escola coloca-se como uma agenda fundamental. É nessa direção que a pedagogia histórico-crítica representa uma referência consistente para este desafio. 


\section{REFERÊNCIAS}

AGÊNCIA ESTADO. Seis estados brasileiros já declararam situação de calamidade financeira. Correio Braziliense, Brasília, 17 jan. 2019. Disponível em:

$<$ https://www.correiobraziliense.com.br/app/noticia/economia/2019/01/17/internas_economia, 731339/seis-estados-brasileiros-ja-declararam-situacao-de-calamidade-financei.shtml>.

Acesso em: 15 dez. 2019.

ARRIZABALO MONTORO, X. Capitalismo y economía mundial: bases teóricas y análisis empírico para la compreensión de los problemas económicos del siglo XXI. Madrid: Instituto Marxista de Economía, 2014.

ASSAD, L. Doenças negligenciadas estão nos países pobres e em desenvolvimento. Ciência e Cultura, São Paulo, v. 62, n. 1, 2010. Disponível em:

$<$ http://cienciaecultura.bvs.br/scielo.php?script=sci_arttext\&pid=S0009-

67252010000100003 >. Acesso em: Acesso em: 15 dez. 2019.

BARATA-MOURA, J. A dialéctica da cientificidade: algumas reflexões para debate. Vértice, Lisboa, n. 20, p. 43-50, nov. 1989.

BRAGA, A. S. Brasil no Mapa da Fome: Voltaremos a ser um país de miseráveis? Fórum, 10 jul. 2017. Acesso em: <http://www.revistaforum.com.br/2017/07/10/brasil-no-mapa-da-fomevoltaremos-ser-um-pais-de-miseraveis/>. Acesso em: 15 dez. 2019.

CANUTO, A.; LUZ, C. R. da S.; ANDRADE, T. V. P. (Coord.). Conflitos no Campo - Brasil 2016. Goiânia: CPT Nacional-Brasil, 2016. 232 p. Acesso em:

<https://www.cptnacional.org.br/index.php/component/jdownloads/download/41-conflitos-nocampo-brasil-publicacao/14061-conflitos-no-campo-brasil-2016>. Acesso em: 15 dez. 2019.

CARNEIRO, F. F. et al. (Org.). Dossiê Abrasco: um alerta sobre os impactos dos agrotóxicos na saúde. Rio de Janeiro: EPSJV; São Paulo: Expressão Popular, 2015. 624 p. Disponível em: <http://www.abrasco.org.br/dossieagrotoxicos/wpcontent/uploads/2013/10/DossieAbrasco_2015_web.pdf>. Acesso em: 15 dez. 2019.

DUARTE, N. A individualidade para si: contribuição a uma teoria histórico-crítica da formação do indivíduo. 3. ed. rev. Campinas: Autores Associados, 2013.

. Entrevista com o professor Dermeval Saviani: Pedagogia Histórico-Crítica na atualidade. Colloquium Humanarum, Presidente Prudente, v. 16, n. 2, p.4-12, abr./jun. 2019.

. O currículo em tempos de obscurantismo beligerante. Revista Espaço do Currículo, João Pessoa, v. 11, n. 2, p. 139-145, 2018a.

. Psicologia histórico-cultural e pedagogia histórico-crítica em tempos de obscurantismo beligerante. In: ORSO, P. J.; MALANCHEN, J.; CASTANHA, A. P. (Org.). Pedagogia histórico-crítica, educação e revolução: 100 anos da Revolução Russa. 2. ed. Uberlândia: Navegando Publicações; Campinas: Autores Associados, 2018b. p. 161-176. 
ENGELS, F. Do socialismo utópico ao socialismo científico. Tradução Roberto Goldkorn. 4. ed. São Paulo: Global, 1981.

. Ludwig Feuerbach e o fim da filosofia alemã clássica. In: MARX, K.; ENGELS, F. Obras escolhidas em três tomos. Tradução José Barata-Moura. Lisboa: Avante, 1985. t. 3. p. 378-421.

FAO. Adopting a Territorial Approach to Food Security and Nutrition Policy. Paris: OECD, 2016. Disponível em: <http://www.keepeek.com/Digital-Asset-Management/oecd/urban-ruraland-regional-development/adopting-a-territorial-approach-to-food-security-and-nutritionpolicy_9789264257108-en\#page4>. Acesso em: 15 dez. 2019.

FRIGOTTO, G. Reforma do Ensino Médio do (des) governo de turno: decreta-se uma escola para os ricos e outra para os pobres. Movimento - Revista de Educação, Rio de Janeiro, ano 3, n. 5, p. 329-332, 2016.

IANDOLI, R. Mundo produz comida suficiente, mas fome ainda é uma realidade. Nexo Jornal, 02 set. 2016. Disponível em: <https://www.nexojornal.com.br/explicado/2016/09/02/Mundoproduz-comida-suficiente-mas-fome-ainda-\%C3\%A9-uma-realidade>. Acesso em: 15 dez. 2019.

IISS. Armed conflict survey. Londres: IISS, 2015. Disponível em:

<https://www.iiss.org/en/publications/acs>. Acesso em: 10 dez. 2015.

JINKINGS, I.; DORIA, K.; CLETO, M. Por que gritamos Golpe? Para entender o impeachment e a crise política no Brasil. São Paulo: Boitempo, 2016.

KUENZER, A. Z. Trabalho e escola: a flexibilização do ensino médio no contexto do regime de acumulação flexível. Educação e Sociedade, Campinas, v. 38, n. 139, p. 331-354, abr./jun. 2017.

LÊNIN, V. I. O imperialismo, fase superior do capitalismo. Tradução José Eudes Baima Bezerra. Brasília: Nova Palavra, 2007.

LEONTEV, A. O desenvolvimento do psiquismo. Lisboa: Horizonte, 1978.

MARX, K. Contribuição à crítica da economia política. Tradução Florestan Fernandes. 2. ed. São Paulo: Expressão Popular, 2008.

. O capital: crítica da Economia Política (Livro 1). Tradução José Barata-Moura, João Pedro Gomes, Pedro de Freitas Leal, Manuel Loureiro e Ana Portela. Lisboa: Avante, 1990. t. 1.

MARX, K.; ENGELS, F. A ideologia alemã: crítica da mais recente filosofia alemã em seus representantes Feuerbach, B. Bauer e Stirner, e do socialismo alemão em seus diferentes 
profetas. Tradução Rubens Enderle, Nélio Schneider, Luciano Cavino Martorano. São Paulo: Boitempo, 2007.

MORSCHBACHER, M. Formação de Professores: proposições para a formação para o Trabalho Científico na Licenciatura em Educação Física. 2016. 363 f. Tese (Doutorado em Educação) - Faculdade de Educação, Universidade Federal da Bahia. Salvador, 2016.

. O tema da ciência na dialética materialista. Germinal: Marxismo e Educação em Debate, Salvador, v. 11, n. 2, p 47-58, abr. 2019.

NACIF, P. G. S.; SILVA FILHO, P. A educação brasileira na mira do obscurantismo e Estado mínimo. In: LEITE, A. Z. et al. Brasil: incertezas e submissão? São Paulo: Fundação Perseu Abramo, 2019. p. 231-249.

SAVIANI, D. Ciência e educação na sociedade contemporânea: desafios a partir da pedagogia histórico-crítica. Revista Faz Ciência, Francisco Beltrão, v. 12, n. 16, p. 13-36, jul./dez. 2010.

. Pedagogia histórico-crítica: primeiras aproximações. 11. ed. rev. Campinas: Autores Associados, 2012.

. Prefácio. In: ARCE, A. (Org.). O trabalho pedagógico com crianças de até três anos. Campinas: Alínea, 2014. p. 5-7.

SAVIANI, D.; DUARTE, N. (Org.). Pedagogia histórico-crítica e luta de classes na educação escolar. Campinas: Autores Associados, 2012.

TERRA. Relatório: guerras continuam sendo principal causa da fome. Terra, São Paulo,12 out. 2015. Disponível em: <http://noticias.terra.com.br/mundo/guerras-continuam-sendo-aprincipal-causa-da-fome-apontarelatorio,12931072972493207248576ea781eef1owtj1vpx.html>. Acesso em: 15 dez. 2019.

UNESCO. UNESCO: 758 milhões de adultos não sabem ler nem escrever frases simples. 16 fev. 2017. Acesso em: <https://nacoesunidas.org/unesco-758-milhoes-de-adultos-nao-sabemler-nem-escrever-frases-simples/>. Acesso em: 15 dez. 2019.

VARGAS, A. A volta da fome. Isto É, 15 nov. 2018. Disponível em: <https://istoe.com.br/avolta-da-fome/>. Acesso em: 15 dez. 2019. 